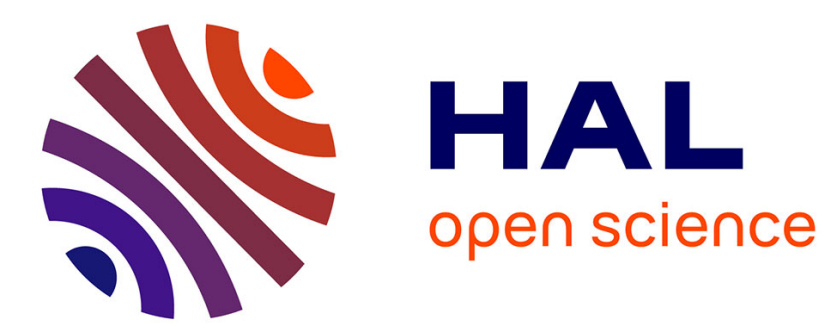

\title{
On the Use of $\mathrm{H} 2$ Plasma for the Cleaning and Passivation of InP Substrates
}

\author{
G. Bruno, M. Losurdo, P. Capezzuto
}

\section{To cite this version:}

G. Bruno, M. Losurdo, P. Capezzuto. On the Use of H2 Plasma for the Cleaning and Passivation of InP Substrates. Journal de Physique IV Proceedings, 1995, 05 (C5), pp.C5-663-C5-670. 10.1051/jphyscol:1995579 . jpa-00253941

\section{HAL Id: jpa-00253941 https://hal.science/jpa-00253941}

Submitted on 1 Jan 1995

HAL is a multi-disciplinary open access archive for the deposit and dissemination of scientific research documents, whether they are published or not. The documents may come from teaching and research institutions in France or abroad, or from public or private research centers.
L'archive ouverte pluridisciplinaire HAL, est destinée au dépôt et à la diffusion de documents scientifiques de niveau recherche, publiés ou non, émanant des établissements d'enseignement et de recherche français ou étrangers, des laboratoires publics ou privés. 
JOURNAL DE PHYSIQUE IV

Colloque C5, supplément au Journal de Physique II, Volume 5, juin 1995

\title{
On the Use of $\mathrm{H}_{2}$ Plasma for the Cleaning and Passivation of InP Substrates
}

\author{
G. Bruno, M. Losurdo and P. Capezzuto \\ Centro di Studio per la Chimica dei Plasmi-CNR, Dipartimento di Chimica-Università di Bari, \\ via Orabona 4, 70126 Bari, Italy
}

\begin{abstract}
The effectiveness of hydrogen plasma for the reduction process of surface native oxide on InP substrates is investigated by X-ray photoelectron spectroscopy (XPS) and by phase modulated spectroscopic ellipsometry (PMSE). H2 plasmas, generated in a quartz tube by applying a r.f. field (13.56 $\mathrm{MHz})$ to external electrodes, produce a very high $\mathrm{H}$-atom flux $\left(5 \cdot 10^{20}\right.$ atoms $\left./ \mathrm{cm}^{2} \mathrm{sec}\right)$ in the downstream region. The ex-situ XPS and in-situ PMSE measurements indicate that the native oxide layer $(25 \AA)$ is completely removed. The end point of the cleaning process is well detected by kinetic ellipsometry. The plasma treated surface shows a higher stability to reoxidation than that observed for wet etches samples.
\end{abstract}

\section{INTRODUCTION}

Low pressure hydrogen plasmas (r.f., MW, ECR) are becoming increasly important in the field of III$V$ semiconductors technology for: i) the removal of surface carbon contamination and native oxide [1, 2], ii) the etching process, when hydrocarbon $\left(\mathrm{CH}_{4}, \mathrm{C}_{2} \mathrm{H}_{6}, \ldots\right)$ are also added $[3,4]$, and iii) the hydrogen passivation of acceptors and defect saturation $[5,6]$.

Recently, much effort has been devoted to the development of $\mathrm{H}_{2}$ plasma dry processes for the preparation of clean and well-ordered InP surfaces for epitaxial growth [7]. With respect to this, the major problems are the surface carbon contamination and the presence of native oxide overlayer. Adsorbed carbon is strongly bonded to the III-V surfaces where it still remains after annealing at high temperature, inducing a free-carrier depletion region at the epilayer-substrate interface. Native oxides on InP surface are detrimental to the formation of stable interfaces and can also induce defected epitaxial growth and, consequently, undesirable electrical characteristics of the devices. The standard cleaning procedures are, sometimes, not able to give reproducible cleaned surfaces. In particular, the "wet chemical etching" [8], by acid solution, is an ex situ procedure not able to remove the carbon contamination completely, the "thermal desorption" [9] requires high temperatures causing partial decomposition of InP substrates, and the "argon ion sputtering" [10] leads to lattice disruption. Alternative in situ $\mathrm{H}_{2}$ plasma treatment, based on the interaction process of $\mathrm{H}$-atoms with the InP surface, are presently under investigation. However, if the H-atoms flux impinging on the surface is not appropriately controlled, the InP substrates can lose their stoichiometry and mirror-like aspect as a consequence of the preferential etching of phosphorus $[11,12,13]$. Hence, in order to achieve high cleanliness and passivation while minimizing damage of the crystal structure, it is becoming important to utilize appropriate diagnostic methods to control the plasma, the H-atom flux onto the surface and the surface modifications.

In this study, results on the in situ cleaning and passivation of InP surfaces by a controlled atomic hydrogen flux present in the downstream region of a low pressure $\mathrm{H}_{2}$ r.f. plasma are reported. The effect of the substrate temperature during plasma treatment has been investigated using in situ Phase Modulated Spectroscopic Ellipsometry (PMSE) and ex situ X-Ray Photoelectron Spectroscopy (XPS). The effectiveness of the remote $\mathrm{H}_{2}$ plasma in the surface cleaning is compared to the conventional wet etching procedure. 


\section{EXPERIMENTAL}

$\mathrm{H}_{2}$ plasma treatments were performed in the home made "remote Plasma MOCVD" (RP-MOCVD) apparatus schematized in fig.1 (details can be found in ref.14).

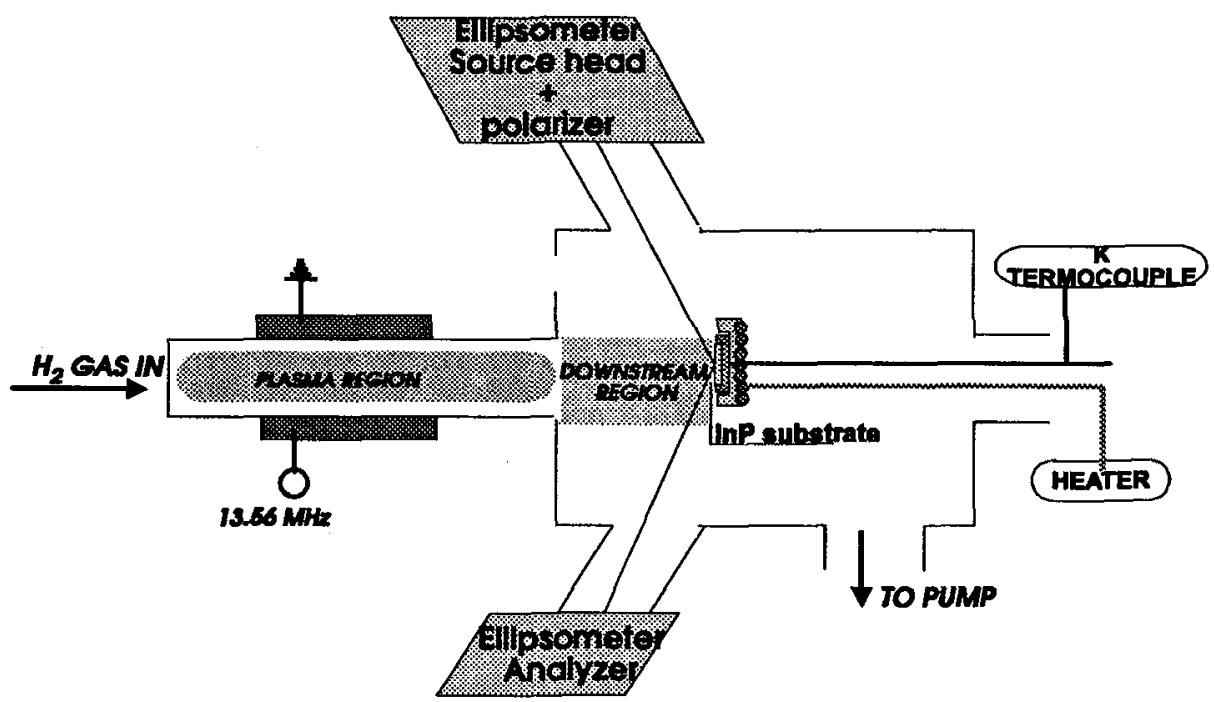

Figure 1: Schematic representation of the RP-MOCVD apparatus.

The $\mathrm{H}_{2}$ r.f. discharge was ignited between two semicircular external electrodes by applying a 13.56 MHz voltage in a $4 \mathrm{~cm}$ i.d. quartz tube. This plasma source is assembled on the stainless-steel MOCVD chamber. In this configuration it is assumed that the plasma region end coincides with the end of the quartz tube. Thus, effects related to plasma radiative damage of InP substrates can be minimized.

The $\mathrm{H}_{2}$ plasma was generated at the pressure of 1 torr, at the r.f. power of 60 watt, and at the flow rate of $800 \mathrm{sccm}$. Before running the cleaning treatments, the inside wall of the plasma tube was covered with a thin film of phosphorus by operating a $\mathrm{PH}_{3}-\mathrm{H}_{2}$ plasma process. This assures the presence of few ppm of $\mathrm{PH}_{3}$ during the cleaning. Few cleaning experiments were done by adding low amounts of $\mathrm{PH}_{3}$ to $\mathrm{H}_{2}$ plasma $\left(\mathrm{PH}_{3} / \mathrm{H}_{2}=10^{-3}-10^{-2}\right)$.

InP plasma cleaning experiments were performed on SI (100) InP provided by Crismatec-InPact. The InP substrate was positioned $10 \mathrm{~cm}$ far from the plasma tube end. The $\mathrm{H}_{2}$ plasma cleaning was performed for $1 \mathrm{~h}$ on substrates at room temperature and at $\mathrm{T}=130^{\circ} \mathrm{C}$, while $7 \mathrm{~min}$ were enough for plasma cleaning at $\mathrm{T}=270^{\circ} \mathrm{C}$. The effectiveness of the $\mathrm{H}_{2}$ plasma in situ dry cleaning was evaluated by a comparison with a wet etched sample obtained by isopropanol washes and DI rinse, followed by chemical etching in a $\mathrm{H}_{2} \mathrm{SO}_{4}: \mathrm{H}_{2} \mathrm{O}_{2}: \mathrm{H}_{2} \mathrm{O}=(8: 1: 1)$ solution at room temperature.

For the process diagnostics, in situ ellipsometric spectra were taken using a Phase Modulated Spectroscopic Ellipsometer (PMSE) (Elli-UVISEL by ISA-JOBIN-YVON) operating in the range 200 $800 \mathrm{~nm}$ [15]. Ellipsometric measurements at fixed wavelenght $(\lambda=269 \mathrm{~nm})$ were used for the kinetic study of the InP cleaning and for the end point detection of the native oxide reduction process.

Ex situ X-ray Photoelectron spectroscopy (XPS) data were collected using a PHI 5300 Perkin-Elmer spectrometer emploing the $\mathrm{Mg}(1253.6 \mathrm{eV}) \mathrm{K} \alpha \mathrm{X}$-ray source. The XPS analysis (smoothing, X-ray satellites subtraction and fitting) was performed on the high resolution $\operatorname{In}_{3} \mathrm{~d}_{5 / 2}, \mathrm{P} 2 \mathrm{p}, \mathrm{O} 1 \mathrm{~s}$ peaks by using the Perkin-Elmer software supplied with the system. 


\section{RESULTS AND DISCUSSION}

\subsection{H-atom plasma source}

Low pressure hydrogen plasmas are good sources of $\mathrm{H}$-atoms, whose density level results from the balance between the direct electron impact dissociation process:

$$
\mathrm{H}_{2}+\mathrm{e} \rightarrow \mathrm{H}+\mathrm{H}+\mathrm{e}
$$

and the recombination processes:

$$
\begin{aligned}
& \mathrm{H}+\mathrm{H}+\mathrm{H}_{2} \rightarrow \mathrm{H}_{2}+\mathrm{H}_{2} \\
& \mathrm{H} \stackrel{\text { wall }}{\longrightarrow} 1 / 2 \mathrm{H}_{2}
\end{aligned}
$$

The extent of these processes is mainly determined, in the plasma volume, by r.f. power and pressure which directly affect the electron energy and density. However, in the plasma downstream (remote plasma conditions) the recombination processes only are effective and, hence, pressure and total flow rate determine the $\mathrm{H}$-atom density decay profile.

Figure 2 shows the $\mathrm{H}$-atom density, $[\mathrm{H}]$, profile evaluated in the plasma downstream flow at different positions in the MOCVD chamber. The $\mathrm{H}$-atom density was derived by the etching rate measurements of a phosphorus film, as the kinetic equation

$$
[\mathrm{H}]\left(\mathrm{cm}^{-3}\right)=(2.1 \pm 0.4) 10^{15} \cdot \mathrm{r}_{\mathrm{E}}(\stackrel{\mathrm{A}}{/ \mathrm{sec}})
$$

was demonstrated to be valid [16]. Details on this method can be found in ref.[17]. Here it is important to underline that the $\mathrm{H}$-atom density in the present system (see fig. 2 ) is much higher $\left(>10^{15} \mathrm{~cm}^{-3}\right.$ ) than that reported by Tachibana [18], who found, in the afterglow region of a similar plasma system, $[\mathrm{H}]$ values ranging between $10^{11}-10^{13} \mathrm{~cm}^{-3}$, depending on the r.f. power, pressure and gas flow. The high efficiency of our $\mathrm{H}$-atom source is related to the high gas flow rate and, hence, to the low residence time $(<1 \mathrm{sec})$ in the afterglow region, where the three-body recombination process (eq.2) controls the $\mathrm{H}$-atom disappearance. Thus, the $\mathrm{H}_{2}$ gas flow rate and the relative position of the InP substrate to be treated are crucial for determining the $\mathrm{H}$-atom flux impinging on the surface.

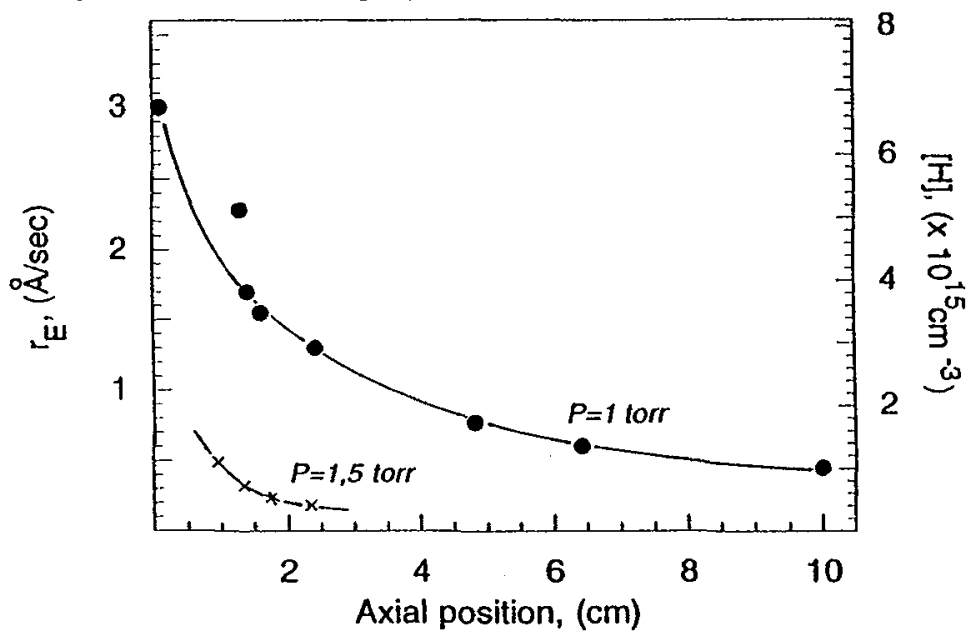

Figure 2: Etching rate of phosphorus, $\mathrm{E}_{\mathrm{E}}$, vs axial position in the downstream flow of $\mathrm{H}_{2}$ plasma at $\mathrm{P}=1$ torr and $\mathrm{P}=1.5$ torr (r.f. power $=60$ watt, gas flow rate $=100 \mathrm{sccm}$ ). $\mathrm{H}$-atom densities have been derived by eq. $(4)$ (see text). 


\section{2. $\mathrm{H}_{2}$ plasma cleaning experiments}

Previous studies $[12,13,17]$ demonstrate that a direct exposure of InP substrate to $\mathrm{H}$-atom flux as high as $10^{17}-10^{18}$ atoms $/ \mathrm{cm}^{2}$. sec induces, even at room temperature, a decomposition of the substrate forming metallic indium droplets. This is a direct consequence of phosphine formation. Here, it is important to underline that in the present remote plasma configuration, the $\mathrm{H}$-atom flux impinging on the InP surface, at the axial position of $10 \mathrm{~cm}$, is about $5 \cdot 10^{20}$ atoms $/ \mathrm{cm}^{2} . \mathrm{sec}$.

A preliminar angle-resolved XPS characterization of the InP native oxide layer shows a layered structure, i.e. the topmost layer mainly includes phosphorus-rich indium phosphates, and the sublayer, at the interface with $\mathrm{InP}$ substrate, is rich in indium oxide, $\operatorname{In}_{2} \mathrm{O}_{3}$. Spectroscopic ellipsometric measurements indicate a native oxide thickness of about $25 \AA$.

Fig. 3 shows the In $3 d_{5 / 2}$ and 01 s core level spectra for the $\mathrm{H}_{2}$ plasma treated and the wet etched substrates. The spectra are acquired at the take-off angle $\Theta=15^{\circ}$, which means that the first $20 \AA$ are sampled. For a comparison, the XPS spectra of the InP untreated substrate are also reported.

In3d $\mathbf{5 / 2}$
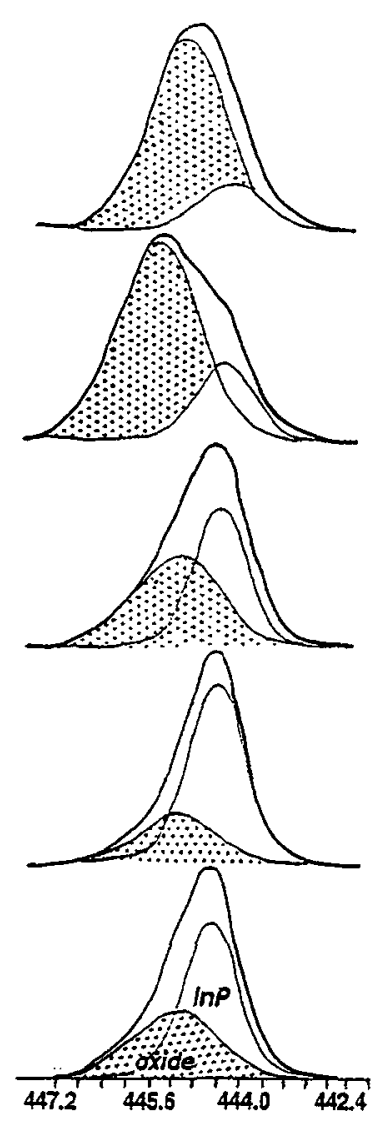

O1s

(a)

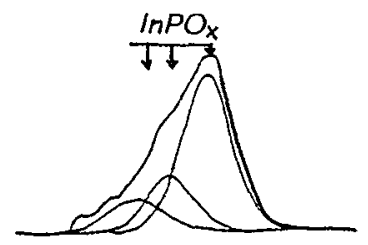

(b)

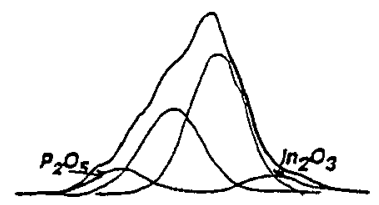

(c)

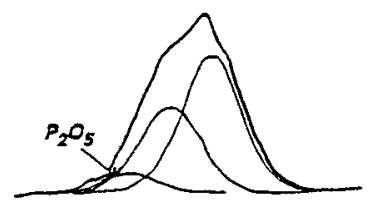

(d)

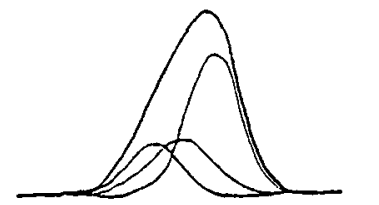

(e)

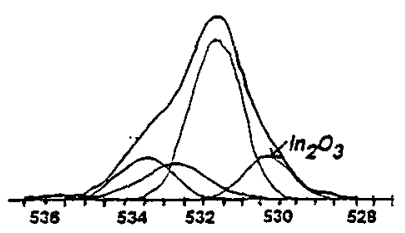

Binding Energy, (eV)

Figure 3: XPS high resolution spectra of In $3 \mathrm{~d} 5 / 2$ and $\mathrm{O} 1 \mathrm{~s}$ photoelectron peaks of (a) untreated InP substrate, and $\mathrm{H}_{2}$ plasma treated InP substrates at (b) $\mathrm{T}=25^{\circ} \mathrm{C}$ for $1 \mathrm{~h}$ (c) $\mathrm{T}=130^{\circ} \mathrm{C}$ for $1 \mathrm{~h}$ (d) $\mathrm{T}=250^{\circ} \mathrm{C}$ for $15 \mathrm{~min}$, and of (d) wet etched sample. 
In order to evaluate the effectiveness of $\mathrm{H}_{2}$ plasma cleaning, the ex-situ XPS analysis is simplified as follow:

(a) the In $3 \mathrm{~d} 5 / 2$ peak is fitted by the component at $444.4 \mathrm{eV}$ due to In-P bond and by a second component, at higher energy, ascribed to oxidized-indium compounds (In-oxide) whose B.E. value depends on their oxidation degree;

(b) the $\mathrm{O} 1 \mathrm{~s}$ peak is deconvoluted to evidence the presence of phosphorus oxide $\mathrm{P}_{2} \mathrm{O}_{5}$ (peak at $534.1 \mathrm{eV}$ ), and indium oxide, $\operatorname{In}_{2} \mathrm{O}_{3}$ (peak at $530.2 \mathrm{eV}$ ), in addition to phosphates $\operatorname{InP}_{\mathrm{x}} \mathrm{O}_{\mathrm{y}}$ (peaks at $531.87 \mathrm{eV}$ and $532.7 \mathrm{eV}$ ).

From core level intensities and by using sensitivity factors, oxygen and carbon contaminations and the overall stoichiometry, In/P, are estimated and reported in Tab.I.

Table I: Compositional ratio, as derived by XPS analysis, for different InP samples.

\begin{tabular}{|c|c|c|c|}
\hline SAMPLE & $\mathbf{I n} / \mathbf{P}$ & $\mathrm{C} /(\operatorname{In}+\mathrm{P})$ & $\mathbf{O} /(\mathbf{I n}+\mathbf{P})$ \\
\hline untreated InP & 0.8 & 8.3 & 1.7 \\
\hline $\begin{array}{c}\mathrm{H}_{2} \text { plasma } 1 \mathrm{~h}-25^{\circ} \mathrm{C} \\
\text { treated InP }\end{array}$ & 0.6 & 5.5 & 2.5 \\
\hline $\begin{array}{c}\mathrm{H}_{2} \text { plasma } 1 \mathrm{~h}-130^{\circ} \mathrm{C} \\
\text { treated InP } \\
\end{array}$ & $\mathbf{0 . 7}$ & 5.9 & 1.5 \\
\hline $\begin{array}{c}\mathrm{H}_{2} \text { plasma } 15 \mathrm{~min}-270^{\circ} \mathrm{C} \\
\text { treated } \mathrm{InP}\end{array}$ & 1.0 & 3.3 & 1.3 \\
\hline wet etched InP & 1.0 & 12 & $\mathbf{3 . 3}$ \\
\hline
\end{tabular}

The results of fig. 3 and Tab.I suggest that the higher the substrate temperature during plasma exposure, the higher the effectiveness of carbon and oxide reduction process. In particular, the $\mathrm{H}_{2}$ plasma cleaning treatment at $\mathrm{T}=270^{\circ} \mathrm{C}$ exhibits InP surface with lower oxygen and carbon contamination than any other treated sample.

The effectiveness of the plasma treatment at $\mathrm{T}=270^{\circ} \mathrm{C}$ is also evidenced by the detailed analysis of the $\mathrm{O} 1 \mathrm{~s}$ spectra. In fact, the $\mathrm{In}_{2} \mathrm{O}_{3}$ oxide component is completely removed, whereas it is still present on the wet etched sample. In addition, the surface analysis of the plasma treated substrates at $\mathrm{T}<130^{\circ} \mathrm{C}$ reveals the presence of $\mathrm{P}_{2} \mathrm{O}_{5}$. The origin of $\mathrm{P}_{2} \mathrm{O}_{5}$ is related to the fact that the $\mathrm{PH}_{3} / \mathrm{H}_{2}$ plasma gives, on the InP surface, deposition of a very thin phosphorus layer, which oxidizes to $\mathrm{P}_{2} \mathrm{O}_{5}$ after air exposure. This phenomenon does not occur at high temperature $\left(270^{\circ} \mathrm{C}\right)$ because of the high phosphorus $\left(\mathrm{P}_{2}\right)$ desorption rate. In addition, at temperature as high as $270^{\circ} \mathrm{C}$, the phosphorus atoms can diffuse into the InP bulk, so eliminating possible defect associated to P-vacancies [18]. In fact, no trace of metallic indium (B.E. $=440.0 \mathrm{eV}$ ) is revealed by the analysis of $\mathrm{In} 3 \mathrm{~d}_{5 / 2}$ peak.

Fig. 4 shows the SE spectra (imaginary part, $\varepsilon_{i}$, of the pseudodielectric function vs energy) recorded, in-situ, for the $\mathrm{H}_{2}$ plasma cleaned sample at $\mathrm{T}=270^{\circ} \mathrm{C}$ and ex-situ for the wet etched substrate; in the same figure the SE spectrum of the untreated substrate is also shown. Using a three-layer (substrate-filmambient) optical model based on the Bruggeman effective medium approximation (BEMA) [19] it is possible to evaluate thickness and composition of the overlayer on the InP substrate. The presence of an oxide layer induces a decrease of the $\varepsilon_{i}$ value at the $E_{2}$ critical point $(4.7 \mathrm{eV})$ and an increase in the region below $3 \mathrm{eV}$. From figure 4, it is evident the large difference of the pseudodielectric function which occurs between $\mathrm{H}_{2}$ plasma treated surface and the wet etched surface. This is indicative of a very different chemical and morphological nature of the InP surface. In fact, the BEMA model gives (see inset 
of fig. 4), for the $\mathrm{H}_{2}$ plasma cleaned sample, a substrate covered by a $\sim 20 \AA$ thick layer of c-InP which includes $15 \%$ of voids. These voids are the consequence of the $\mathrm{O}$-atoms removal process:

$$
2 \mathrm{H}+\mathrm{O}(-\operatorname{In} \mathrm{P}) \rightarrow \mathrm{H}_{2} \mathrm{O}+\operatorname{InP}
$$

in which $\mathbf{H}$-atoms impinging on the surface can diffuse in the material and react with oxygen to produce $\mathrm{H}_{2} \mathrm{O}$. The subsequent diffusion-desorption of $\mathrm{H}_{2} \mathrm{O}$ is, probably, the rate limiting step controlling the overall kinetics. On this last aspect more investigation are needed, expecially on the substrate temperature effect.

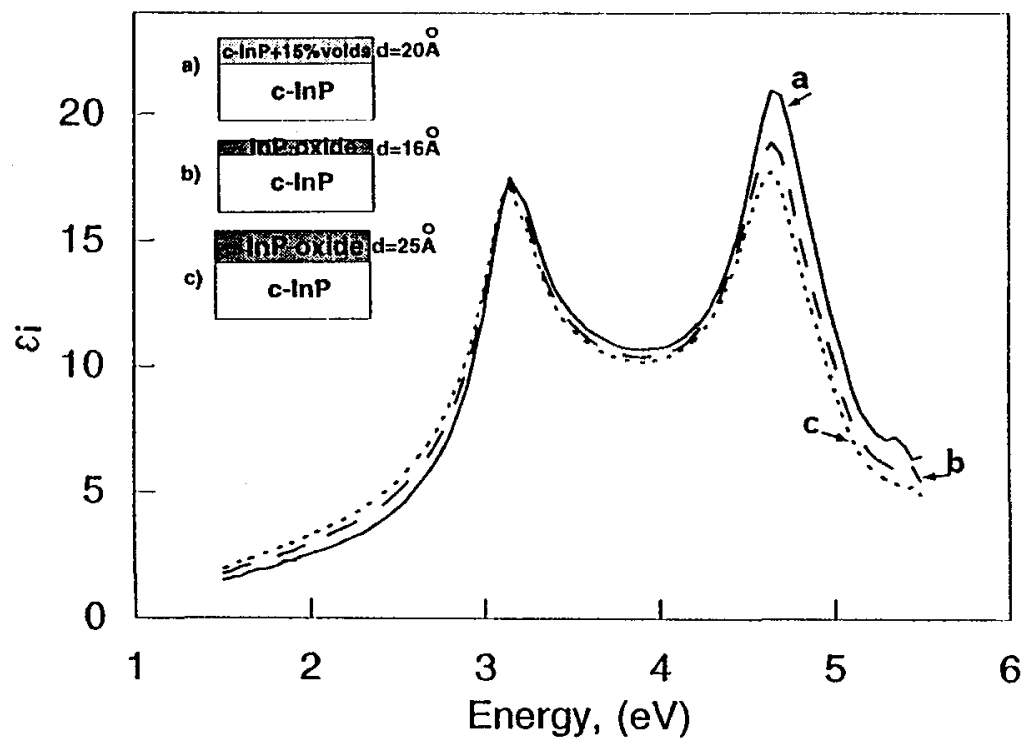

Figure 4: Ellipsometric spectra of the imaginary part, $\varepsilon_{i}$, of the pseudodielectric function, for (a) the plasma treated InP surface, (b) wet cleaned InP surface, and (c) for the "as received" InP substrate. The inset shows the correspondent film structures as derived by BEMA model [19].

For the wet etched sample (see curve b of fig. 4) a residual oxide layer of $16 \AA$ is still present on the InP substrate, though the SE spectrum is recorded soon after the cleaning.

These results clearly indicate that no plasma induced structural damage and no preferential phosphorus etching was observed even at temperature as high as $270^{\circ} \mathrm{C}$ and at $\mathrm{H}$-atom flux as high as 5 $10^{20}$ atoms $/ \mathrm{cm}^{2} \mathrm{sec}$. The preservation of the good surface morphology is due to the fact that, in the present plasma configuration, the InP substrate is not directly exposed to ion bombardment. Also, the presence of few ppm of $\mathrm{PH}_{3}$ in the $\mathrm{H}_{2}$ gas feed is sufficient to preserve InP stoichiometry.

Furtherly, plasma treated InP substrates exhibit a higher stability to reoxidation. This is well evidenced by the lowering of both the oxide thickness measured by SE and the oxide component in the In $3 d_{5 / 2}$ XPS spectra as recordered after two mounths of air exposure. In addition, the analysis of the O1s core level demonstrates that, during the reoxidation, the $\operatorname{In}_{2} \mathrm{O}_{3}$ formation on the InP surface treated with $\mathrm{H}_{2}$ plasma at $\mathrm{T}=270^{\circ} \mathrm{C}$, is suppressed. These last phenomena seems to indicate a sort of stabilizing effect of the InP surface, i.e. H-atoms act for the indium-defect saturation and passivation. 


\subsection{End point detection of the plasma cleaning process}

Real time in-situ ellipsometric measurements at the fixed wavelenght of $270 \mathrm{~nm}(4.6 \mathrm{eV})$ are well adapt to follow the kinetics of the plasma cleaning process. SE'measurement at $4.6 \mathrm{eV}$ is very sensitive to surface modification, since the optical penetretion depth is about $20 \mathrm{~A}$.

Fig. 5 shows the time dependence of $\varepsilon_{\mathrm{i}}(4.6 \mathrm{eV})$ during the plasma treatment with $\mathrm{PH}_{3} / \mathrm{H}_{2}$ mixtures at different $\mathrm{PH}_{3}$ amount: $\mathrm{PH}_{3} / \mathrm{H}_{2}=0.2 \%$ (BC curve), $\mathrm{PH} 3 / \mathrm{H} 2=1 \%$ (CD curve) and $\mathrm{PH}_{3} / \mathrm{H}_{2}=50 \mathrm{ppm}$ (DE curve).

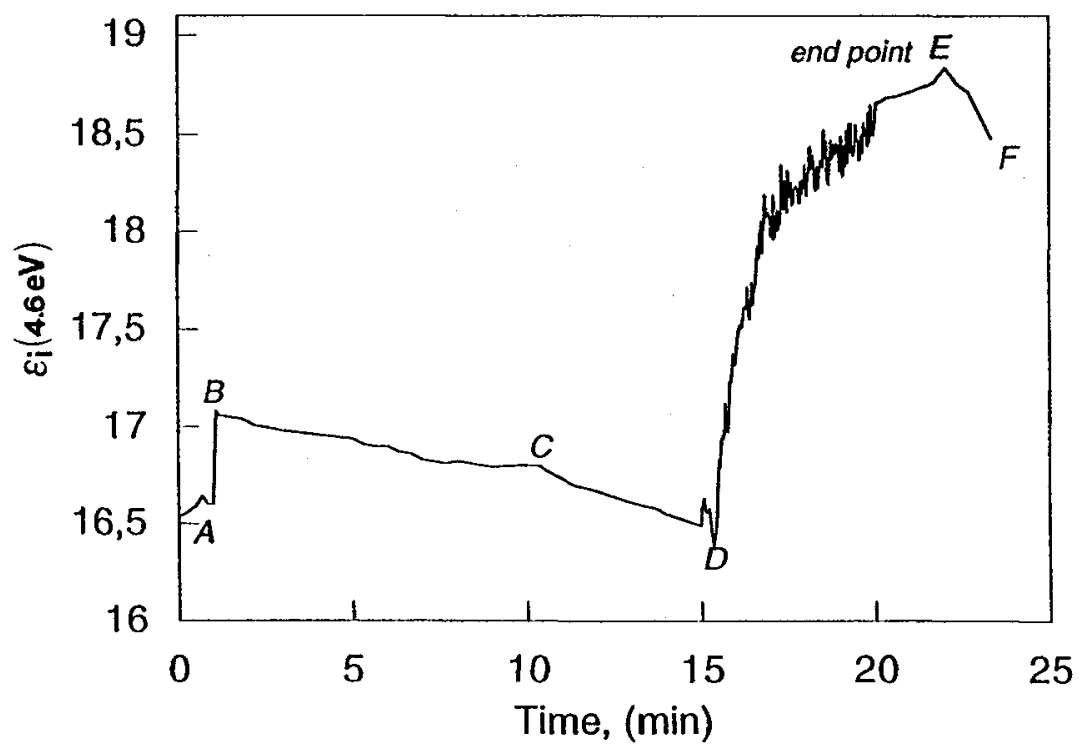

Figure 5: Time evolution of $\varepsilon_{\mathrm{i}}(4.6 \mathrm{eV})$ during $\mathrm{PH}_{3} / \mathrm{H}_{2}$ plasma treatment of $\operatorname{InP}$ substrate at $\mathrm{T}=270^{\circ} \mathrm{C}$, r.f power $=60$ wath gas flow rate $=800 \mathrm{sccm}$, and at different $\mathrm{PH}_{3} / \mathrm{H}_{2}$ ratio: (a) $\mathrm{PH}_{3} / \mathrm{H}_{2}=0.2 \%\left(\mathrm{BC}\right.$ curve), $\mathrm{PH}_{3} / \mathrm{H}_{2}=1 \%$ (CD curve) and $\mathrm{PH}_{3} / \mathrm{H}_{2}=50 \mathrm{ppm}$ (DE curve).

The observed $\varepsilon_{\mathrm{i}}$ decrease, at $\mathrm{PH}_{3}$ percentage higher than hundreds of ppm, indicates that phosphorus deposition occurs on the InP substrate. On the contrary, the $\varepsilon$ i value starts to increase (D point in fig. 5) when the $\mathrm{PH}_{3}$ amount in the feed is reduced to $50 \mathrm{ppm}$. Under this last condition, the H-atoms predominate on the $\mathrm{PH}_{\mathrm{X}}$ radicals (building block for phosphorus deposition) and, hence, the reduction process overcomes the phosphorus deposition. As soon as the oxide layer is completely removed, the $\mathrm{H}$ atoms induce roughness of InP surface so causing a decrease of the $\varepsilon_{\mathrm{i}}$ value (EF curve). Thus, point $\mathrm{E}$ represents the end point detection of the cleaning process.

In concluding this section, it is important to underline that the native oxide reduction process by $\mathrm{H}$ atoms is very effective but needs to be appropriately controlled to avoid film deposition and/or surface roughning. 


\section{References}

[1] A. J. Nelson, S. Frigo, D. Mancini, R. Rosenberg, J. Appl. Phys. 70 (10) (1991) 5619.

[2] J.S. Harman, J. Vac. Sci. \& Technol. A, 11(4) (1993) 1094.

[3] C. Constantine, D. Johnson, S.J. Pearton, U.K. Chakrabarti, A.B. Emerson, W.S. Hobson, A.P. Kinsella, J. Vac. Sci. Technol. B, 8(4) (1990) 596.

[4] J.Werking, J. Schramm, C. Nguyen, E.L. Hu, H. Kroemer, Appl. Phys. Lett. 58(18) (1991) 2003.

[5] T. Sugino, H. Ninomiya, T. Yamada, J. Shirafuji, K. Matsuda, Appl. Phys. Lett. 60 (10) (1992) 1226.

[6] T. Sugino, H. Yamamoto, J. Shirafuji, Jap. J. Appl. Phys. 30 (6A) (1991) L948.

[7] P.G. Hofstra, D.A. Thompson, B.J. Robinson, R.W. Streater, J. Vac. Sci. Technol.B 11(3) (1993) 985.

[8] A Guivarc'h, H. L'Haridon, G. Pelous, G. Hollinger, P. Pertosa, J. Appl. Phys. 55 (4) (1984) 1139.

[9]R. Averbeck, H. Riechert, H. Schlotterer, G. Weimann, Appl. Phys. Lett. 59 (14) 1732 (1991).

[10] J.B. Malherbe, W.O. Barnard, Surface Science, 255 (1991) 309.

[11] D. Gallet, G. Hollinger, C. Santinelli, L. Goldstein, J. Vac. Sci. Technol. B 10 (4) (1992) 1267.

[12] E.J. Petit, F. Houzay, J.M. Moison, Surface Science, 269/270 (1992) 902.

[13] O. M'Hamedy, F. Proix, J.P. Lacharme, C.A. Sebenne, Surface Science 199 (1988) 121.

[14] M. Losurdo, "Crescita di film sottili con processi MOCVD (Metalorganic Chemical Vapor Deposition). Studio di un sistema non convenzionale per la crescita del fosfuro di indio (InP)", tesi di dottorato in Scienze Chimiche, Università di Bari, Italy, (1995).

[15] G. Bruno, M. Losurdo, P. Capezzuto, J. Vac. Sci. \& Technol. A, 13(2) (1995) 1.

[16] G. Bruno, M. Losurdo, P. Capezzuto, Appl. Phys. Lett, to be published.

[17] R.P.H. Chang, C.C. Chang, S. Darack, J. Vac. Sci. \& Technol, 20 (1) (1982) 45.

[18] T. Sugino, Y. Sakamoto, T. Sumiguchi, K. Nomoto, J. Shirafuji, Jpn. J. Appl. Phys. 32 (9A) (1993) L1196.

[19] D.A.G. Bruggeman, Ann. Phys., 24 (1935) 636. 